\title{
Delayed macular hole formation after demarcation laser photocoagulation for subclinical retinal detachment
}

This article was published in the following Dove Press journal:

Clinical Ophthalmology

13 May 2014

Number of times this article has been viewed

\author{
Irene M Rusu' \\ Jessica Zizva² \\ Jane S Myung ${ }^{3}$ \\ Kenneth Wald ${ }^{3}$ \\ 'Department of Ophthalmology, New \\ York University School of Medicine, \\ ${ }^{2} \mathrm{New}$ York University, College \\ of Liberal Arts, ${ }^{3}$ Department of \\ Ophthalmology, New York University \\ School of Medicine, Manhattan Eye, \\ Ear, and Throat Hospital, Retina \\ Associates of New York, New York, \\ NY, USA
}

\begin{abstract}
The purpose of this paper is to report a series of macular holes that developed after demarcation laser photocoagulation for subclinical retinal detachments. This observational case series consists of three eyes from three patients seen between 2005 and 2012. Delayed idiopathic macular hole formation occurred following demarcation laser photocoagulation for subclinical retinal detachment. Demarcation laser photocoagulation of subclinical retinal detachments may predispose to macular hole formation.
\end{abstract}

Keywords: macular hole, demarcation laser photocoagulation, retinal detachment

\section{Introduction}

Unlike large, symptomatic retinal detachments that are almost always treated by surgical repair, the standard treatment for small, subclinical retinal detachments is not as well defined. A recent review of retinal surgical practices in the UK showed that surgery was the most commonly recommended management for asymptomatic retinal detachment, followed by demarcation laser photocoagulation (DLP), and thirdly, by observation alone. ${ }^{1}$

The popularity of DLP is growing as surgeons search for less invasive ways to manage certain types of retinal detachment. A recent case series showed that DLP is an effective method to manage acute or chronic primary or recurrent maculasparing rhegmatogenous retinal detachments without associated proliferative vitreoretinopathy. ${ }^{2}$ Another study expanded on these findings by showing that DLP is an effective alternative to scleral buckling or vitrectomy for treating asymptomatic rhegmatogenous retinal detachment but not for symptomatic rhegmatogenous retinal detachment. ${ }^{3}$ However, most of these studies evaluated the effectiveness of DLP by simply looking at the progression of the retinal detachment after treatment. Other sequelae of DLP are still widely unknown. One recent report suggested that DLP for rhegmatogenous retinal detachment may promote retinal neovascularization. ${ }^{4}$ Macular hole formation after DLP has never been reported. We describe here three cases of DLP for subclinical retinal detachment followed by idiopathic macular hole formation within 1.5 years of treatment.

\section{Case series}

The charts of three patients who presented with idiopathic macular holes from October 2005 to July 2012 were examined. All three patients had a history of DLP in the same eye for subclinical retinal detachment involving the superotemporal retina.
New York University School of

Medicine, 462 First Avenue, NBV 5N18

New York, NY I0016, USA

Email irenerusu@gmail.com 
Subclinical retinal detachment was defined as subretinal fluid extending at least one disc diameter away from the nearest retinal break but not more than two disc diameters posterior to the equator. ${ }^{5}$

Specific patient characteristics are summarized in Table 1. While all three patients had posterior vitreous detachments on examination, a complete Weiss ring was not documented. Patient 1 developed an idiopathic macular hole one year after DLP and also had a history of retinal tear treated with laser in the fellow eye (Figure 1). After the macular hole repair surgery, her vision in the affected eye was 20/150. She was phakic. Preoperative optical coherence tomography confirmed the presence of a temporal epiretinal membrane. Post cataract surgery vision in the affected eye was 20/40. Patient 2 was also phakic in the affected eye at the time of macular hole repair. Her vision post cataract surgery was $20 / 25$. She also had a history of retinal tear treated with laser in the fellow eye. Patient 3 developed a full-thickness macular hole, approximately 800 microns in diameter, after DLP for a subclinical retinal detachment in the superotemporal retina of the same eye. This patient had a history of myopia. All patients underwent DLP prior to idiopathic macular hole formation. None had a history of trauma. Macular hole was identified clinically and by optical coherence tomography evidence.

\section{Discussion}

The etiology of macular hole formation includes a wide variety of factors. Trauma, tractional forces at the vitreofoveal interface, and aging have all been implicated in development of macular hole. Recently, eyes with increased axial length and thus greater dynamic forces at the macula have also been associated with increased macular hole formation. ${ }^{6} \mathrm{We}$ present a series of three patients who developed an idiopathic macular hole after DLP.

Certain factors may predispose to delayed macular hole formation in eyes following DLP. For instance, a horseshoe tear with antecedent vitreous separation was present in two of the three cases we present. The authors have rarely found macular hole formation occurring after laser treatment of typical retina tears. Since the DLP procedure is relatively uncommon compared with the treatment of horseshoe tear, there must be a much higher incidence of macular hole following DLP than prophylactic laser for horseshoe tear. One hypothesis could be related to the presence of subretinal fluid. While the ongoing exposure of the vitreous and macular interface to factors in the subretinal fluid could activate contractile elements around the fovea, there are patients with chronic untreated rhegmatogenous retinal detachment and chronic subretinal fluid as well as individuals with lasered holes with large rims of subretinal fluid who have no increased incidence of macular hole formation.

Additionally, a detached retina in a symptomatic retinal detachment or a subclinical retinal detachment has decreased blood supply from the underlying choroidal vessels. Using laser photocoagulation to wall off the detached retina may further aggravate the ischemia of the detached retina and result in increased structural and tractional forces at the vitreofoveal interface predisposing to macular hole formation. Eyes may have microscopically altered vitreoretinal architecture predisposing them to increased strain at the vitreofoveal interface following DLP. This idea is supported by the fact that all three of our patients had DLP in the superotemporal quadrant, suggesting that this location plays a role in altering vitreous forces. The photocoagulation scars themselves may exert tension on the retinal surface or vitreous as they fibrose, creating increased tractional forces at the macula. The delayed nature of the macular hole formation in our case series supports this hypothesis because the contraction of scars occurs slowly over time.

Our study has a number of limitations related to causality. While all the patients in our series had posterior vitreous detachments, a complete Weiss ring was not documented on examination. Thus, it is possible that formation of the macular hole was in part due to a residual vitreomacular attachment that later released. This sequela would be expected because

Table I Patient characteristics

\begin{tabular}{|c|c|c|c|c|c|c|c|c|}
\hline & $\begin{array}{l}\text { Age, } \\
\text { years }\end{array}$ & Sex & Retinal tear & Area detached & $\begin{array}{l}\text { Time from } \\
\text { DLP to } M H\end{array}$ & $\begin{array}{l}\text { VA post } \\
\text { MH repair }\end{array}$ & $\begin{array}{l}\text { Lens status } \\
\text { at time of RD }\end{array}$ & $\begin{array}{l}\text { VA pre } \\
\text { MH repair }\end{array}$ \\
\hline Patient I OS & 56 & Female & $\begin{array}{l}\text { Large horseshoe tear } \\
\text { superotemporally along } \\
\text { a lattice lesion }\end{array}$ & Superotemporal & 17 months & $20 / 150$ & Phakic & $20 / 100$ \\
\hline Patient 2 OD & 70 & Female & Horseshoe tear at 10 o'clock & Superotemporal & 14 months & $20 / 25$ & Phakic & $20 / 40$ \\
\hline Patient 3 OD & 56 & Female & $\begin{array}{l}\text { Horseshoe tear } \\
\text { superotemporally }\end{array}$ & Superotemporal & 12 months & $20 / 80$ & Phakic & $20 / 400$ \\
\hline
\end{tabular}

Abbreviations: VA, visual acuity; RD, retinal detachment; $\mathrm{MH}$, macular hole; DLP, demarcation laser photocoagulation; OS, left side; OD, right side. 

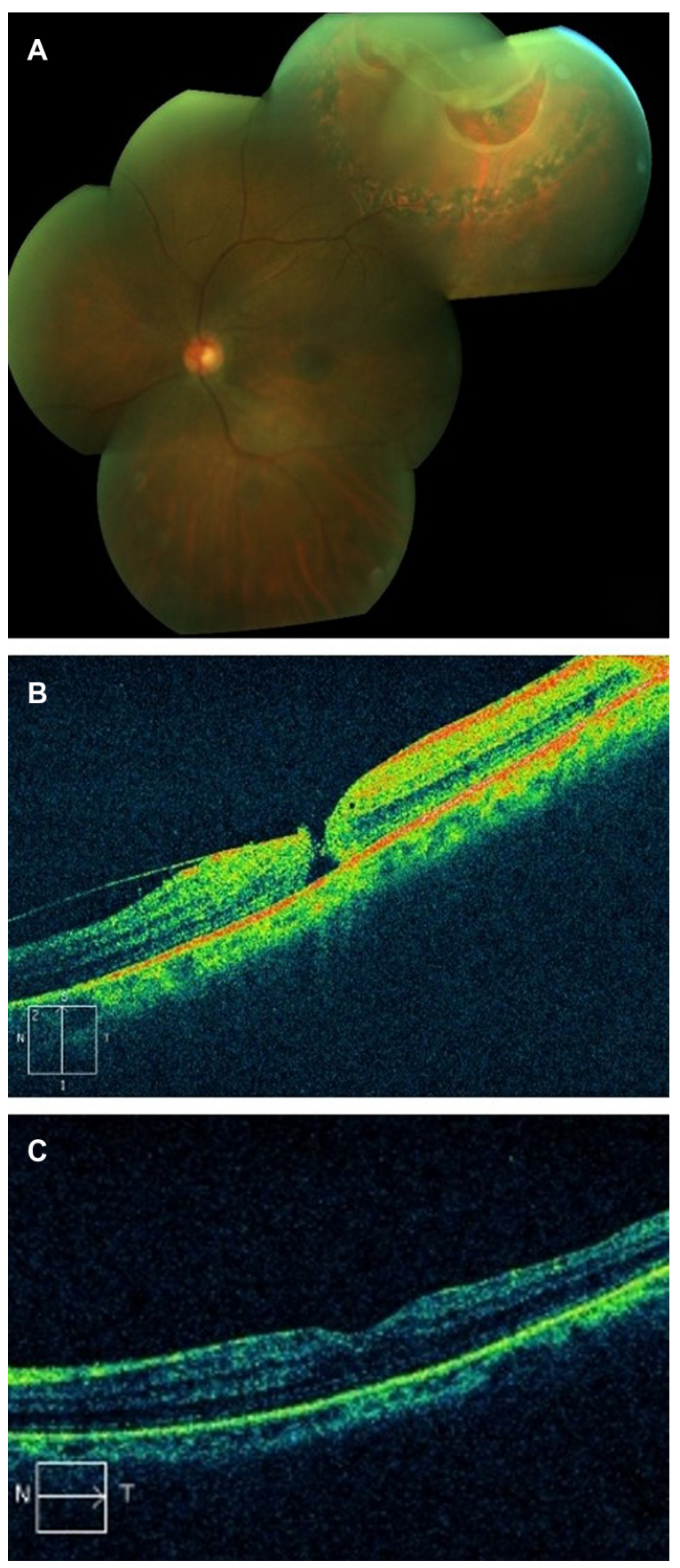

Figure I (A) Wide field fundus photograph showing a large horseshoe tear in the superotemporal area after demarcation laser photocoagulation barricade. (B) Time domain optical coherence tomography of the left eye showing a full thickness macular hole with an epiretinal membrane. (C) Time domain optical coherence tomography of the left eye showing regression of the macular anatomy to normal after macular hole repair. flap or horseshoe tears can occur in the periphery with the posterior hyaloid face still being attached to other parts of the periphery or the macula. Additionally, patient 3 was noted to have a history of myopia which is an independent risk factor for the development of macular holes. Indeed, this patient had a younger than expected age at presentation. Patient 1 was noted to have an epiretinal membrane. However, no vitreoretinal traction was noted on optical coherence tomography. Finally, all the patients in our study were women. Despite the presence of these other related entities that may predispose to macular hole formation, it is significant that the macular holes developed within 17 months of DLP for subclinical retinal detachment. None of the patients in our series had a history of trauma during this timeline, suggesting that DLP may also predispose to the formation of these macular holes. Thus, patients with additional risk factors such as an epiretinal membrane or a myopic fundus may be at increased risk of macular hole formation after DLP.

To the authors' knowledge, formation of macular holes following DLP has never been reported. As a wider range of retinal detachments are being managed with DLP, it is important to note the longer-term effects of this increasingly popular treatment. The exact mechanism involved in the development of a macular hole following DLP still needs to be determined.

\section{Disclosure}

The authors report no conflicts of interest in this work.

\section{References}

1. Ahmad N, West J. Current opinion on treatment of asymptomatic retinal detachments. Eye (Lond). 2007;21:1179-1185.

2. Vrabec T, Baumal C. Demarcation laser photocoagulation of selected macula-sparing rhegmatogenous retinal detachments. Ophthalmology. 2000;107:1063-1067.

3. Al-Mohtaseb Z, Heffez JL, Carvounis PE, Holz ER. Laser demarcation photocoagulation for rhegmatogenous retinal detachments. Eye (Lond). 2010;24:1772-1776.

4. Chen Y, Li C, Chen S. Retinal neovascularization and an angioma-like lesion after demarcation photocoagulation for rhegmatogenous retinal detachment. Chang Gung Med J. 2006;29:212-215.

5. Byer N. Subclinical retinal detachment resulting from asymptomatic retinal breaks. Ophthalmology. 2001;108:1499-1504.

6. Singh AJ, Muqit MM, Woon WH. Is axial length a risk factor for idiopathic macular hole formation? Int Ophthalmol. 2012;32:393-396.

\section{Clinical Ophthalmology}

\section{Publish your work in this journal}

Clinical Ophthalmology is an international, peer-reviewed journal covering all subspecialties within ophthalmology. Key topics include: Optometry; Visual science; Pharmacology and drug therapy in eye diseases; Basic Sciences; Primary and Secondary eye care; Patient Safety and Quality of Care Improvements. This journal is indexed on

\section{Dovepress}

PubMed Central and CAS, and is the official journal of The Society of Clinical Ophthalmology (SCO). The manuscript management system is completely online and includes a very quick and fair peer-review system, which is all easy to use. Visit http://www.dovepress.com/ testimonials.php to read real quotes from published authors. 